\title{
ANÁLISES MORFOLÓGICAS E MOLECULARES REVELAM UMA NOVA ESPÉCIE ENDOLÍTICA DE CAMARÃO-DE-ESTALO (CARIDEA: ALPHEIDAE) PARA O ATLÂNTICO SUL OCIDENTAL
}

\author{
Santos, P.S. ${ }^{1,}{ }^{*}$; Terossi, M. ${ }^{2}$; Mantelatto, F.L. ${ }^{3}$ \& Almeida, A.O. ${ }^{1}$ \\ ${ }^{1}$ Universidade Federal de Pernambuco (UFPE), Campus Recife, Laboratório de Biologia de Crustáceos. \\ ${ }^{2}$ Universidade Federal do Rio Grande do Sul (UFRGS), Campus do Vale, Laboratório de Carcinologia. \\ ${ }^{3}$ Universidade de São Paulo (USP), Faculdade de Filosofia, Ciências e Letras de Ribeirão Preto (FFCLRP), Campus de \\ Ribeirão Preto, Laboratório de Bioecologia e Sistemática de Crustáceos. \\ *Autor correspondente: pssantosuesc@gmail.com
}

\begin{abstract}
Os camarões da família Alpheidae Rafinesque, 1815 incluem inúmeros complexos de espécies crípticas. Estudos envolvendo essa problemática possibilitaram o esclarecimento sobre a distribuição de algumas espécies que primariamente apresentavam distribuição geográfica controversa. Alpheus simus Guérin-Méneville, 1855 é um camarão-de-estalo que ocorre no Atlântico Ocidental, onde sua distribuição conhecida é disjunta: da Flórida ao sul do Mar do Caribe e no Brasil, do Rio Grande do Norte até a Bahia, configuração que traz indícios da existência de um complexo de espécies. Ao examinar um conjunto de espécimes atribuídos à $A$. simus e espécies morfologicamente relacionadas, verificou-se que o material proveniente da Bahia previamente identificado como A. simus apresentava caracteres morfológicos distintos. Com isso, o objetivo deste trabalho é a descrição de uma nova espécie endolítica de camarão-de-estalo do gênero Alpheus Fabricius, 1798. Os espécimes foram coletados no Parque Municipal Marinho do Recife de Fora, Porto Seguro, Bahia, Brasil. Alpheus sp. n. pertence ao grupo obesomanus e é morfologicamente semelhante a A. simus (Atlântico Oeste) e Alpheus saxidomus Dana, 1852 (Pacífico Leste). Porém, difere destas principalmente por apresentar diferença no comprimento e na morfologia do escafocerito. Esses resultados foram sustentados por dados moleculares (gene mitocondrial Citocromo Oxidase subunidade I), tanto pelas distâncias genéticas (Kimura 2 Parâmetros) quanto pela árvore filogenética gerada pela análise de máxima verossimilhança de sequências. Com isso, confirma-se a existência de uma nova espécie derivada do complexo de espécies envolvendo A. simus sensu stricto.
\end{abstract}

Palavras-chave: $\mathrm{COI}$, grupo Obesomanus, fauna críptica.

Financiamento: CAPES, CNPq, FACEPE, FAPESP. 